\title{
Factors influencing Nigerian men's decision to undergo prostate specific antigen testing.
}

\author{
Oghenetejiri Ubrurhe Enaworu, Ranjit Khutan
}

Faculty of Education, Health and Wellbeing, University of Wolverhampton.

\begin{abstract}
Background: Prostate cancer is a major cause of cancer death in Nigerian men. Attempts to reduce mortality from prostate cancer have focused mainly on early detection of the disease by the use of PSA testing. As a result of the increased incidence of prostate cancer in Nigeria despite the widespread availability of testing facilities, it became pertinent to understand the salient factors that prompt Nigerian men to go for prostate cancer testing.

Objective: This study explores the factors that influence a group of Nigerian men's decision to go for Prostate Specific Antigen (PSA) testing.

Methods: Following ethical approval, semi structured interviews were conducted with a group of 10 men who had PSA test following consultation with their doctor with signs and symptoms at the University of Benin Teaching Hospital from July to August, 2010. Interview transcripts were analysed by employing steps proposed by Collaizi (1978).

Results: Five themes were identified: the symptoms experienced, the influence of friends and relatives, older age associated with increased awareness, accessibility to testing services and the knowledge of the PSA test.

Conclusion: The study revealed that there continues to be a considerable lack of awareness and knowledge about prostate cancer and screening.

Keywords: Prostate cancer, Specific Antigen Testing (PSA), University of Benin Teaching Hospital, older men, Nigerian men. DOI: http://dx.doi.org/10.4314/ahs.v16i2.21

Cite as: Enaworu OU, Khutan R. Factors influencing Nigerian men's decision to undergo prostate specific antigen testing. Afri Health Sci 2016;16(2): 524-532. bttp://dx.doi.org/10.4314/abs.v16i2.21
\end{abstract}

\section{Background}

Prostate cancer is recognised as a large and growing public health issue facing the male population across the globe. It is the second major cause of cancer associated death amongst men ${ }^{1}$. In the United States, it is the prevailing potential life-threatening cancer especially amongst African American men who possess the highest rates in the world ${ }^{2}$. Cancer morbidity and mortality data in Nigeria is unavailable as a result of the absence of national cancer registry ${ }^{3}$. However, the evidence in the literature indicates that prostate cancer is the most commonly diagnosed cancer amongst Nigerian men ${ }^{4,5}$. The higher morbidity and mortality in Nigerian men maybe associated with late presentation at the hospital and being diagnosed at a much older age than men in developed countries ${ }^{6}$. Other
Corresponding author:
Oghenetejiri Ubrurhe Enaworu,
Faculty of Education, Health and Wellbeing,
University of Wolverhampton.
Email: tj2see@yahoo.com

reasons for the higher prostate cancer rates seen in this population include: absence of screening programmes, inadequate diagnostic facilities, ignorance and poverty and the assumption that lower urinary tract symptoms are part of ageing process ${ }^{7}$. It is these issues, coupled with genetic factors, which lead to a higher prevalence of this cancer amongst Nigerian men and therefore the need for further understanding in this area.

Despite the advent of serum Prostate Specific Antigen (PSA) used as a tumour marker for prostate cancer, controversy regarding its use for prostate cancer screening persists ${ }^{8}$. The European Randomised Study of Screening for Prostate cancer (ESPRC) carried out to terminate the controversy surrounding testing revealed that death rates from prostate cancer can be decreased but at the expense of substantial over diagnosis and over treatment?. While the Prostate, Lung, Colorectal and Ovarian (PLCO) cancer screening trial undertaken by Andriole et al. ${ }^{10}$ in the same vein, discovered no appreciable difference in the mortality rates from prostate cancer between the screening and control group. Although, there is insufficient 
evidence demonstrating the benefits of prostate cancer screening, the studies by Bartsch et al. ${ }^{11}$ and Horninger et $a l .^{12}$ revealed that the survival rate of men who engaged in prostate cancer screening and treatment were enhanced compared to those who did not undergo screening. The recommended age by the American Urological Association for PSA testing was reduced to 40 years because measurement for PSA level is more specialised for younger than older men ${ }^{13}$. It has being recommended that since there are no glaring symptoms for early prostate cancer; early detection should be prompted in 'at-risk' men, in this case Nigerian men $^{14}$.

This study aimed to identify the salient factors that influenced a group of Nigerian men's decision to go for PSA testing. The findings offer insight into the factors influencing these men's decision to go for screening and as a result, these findings will help guide in designing effective, culturally sensitive and relevant interventions towards increasing the uptake of screening and further trigger investigations targeted at improving treatment options.

\section{Methods}

This was a qualitative study which adopted the use of semi structured interviews to elicit the views of participants in line with the epistemological position of the study. A purposive sampling strategy was used to recruit participants for the study. Participants were Nigerian males between the ages of 40 - 60 years, who came for PSA testing at the Urology Department of the University of Benin Teaching Hospital from July to August, 2010. All were well educated, able to read and speak English fluently and were socio-economically at average or above level. The decision to focus on men in this age range was informed by the recommendation made by the American Urological Association ${ }^{14}$.

The University of Benin Teaching Hospital (UBTH) was best suited for the study because it is one of the biggest hospitals in the Niger Delta Region of Nigeria. It is the sixth of the first generation hospital, established to complement the University of Benin medical and provides care to the Edo-Delta region and the surrounding cities ${ }^{15}$. Furthermore, it provides innovative technology for training purposes for high and middle level manpower and also leads research opportunities for the university and other interested individuals. UBTH, which is located on the Benin-Lagos expressway ${ }^{15}$ is situated in Benin City comprising predominantly of Benin ethnic group and the indigenous language, been Benin, however, other ethnic groups live in the city. The hospital runs a urology clinic which is open to out-patients twice a week, admits cases and regularly receives referrals from other hospitals.

Ethical approval to conduct the study was obtained from the ethics committee of the School of Health \& Wellbeing at the University of Wolverhampton, England (UK). In addition, approval to carry out the study was obtained from the Chief Medical Director, University of Benin Teaching Hospital, Nigeria. Eligible participants were those who visited the urology clinic and referred for PSA testing by their doctor. At this time, they were informed about the study and invited to take part. Those willing to engage in the study were directed to the researcher. The researcher provided them with an information sheet and verbal explanations where necessary to enable them make an informed decision on whether to participate in the study or not. Potential participants were allowed to take away the information sheet, those willing to partake in the study contacted the researcher by phone, and interview dates convenient for each participant were fixed. On interview days, informed consent was obtained from participants by them signing the general consent and right to withdraw form before the interview commenced. They were further informed that their consent could be withdrawn at any stage during the study. The recruitment process continued until data saturation was obtained. Ten participants who met the inclusion criteria were interviewed; two of these took part in the pilot study and were included in the main sample.

To maintain anonymity and confidentiality, the participants are referred to as participants A-J. Interviews were carried out on the hospital premises. Furthermore, participants were reassured that information would not be divulged to other personnel, except those directly involved in the study. The interview questions were designed to enable participants to openly discuss a number of factors related to this study. Questions centred around the factors that prompted them to present to the hospital for testing, what they feel hinders them from accessing testing services, gain an understanding of their knowledge 
on PSA testing, obtain their perception on early testing and enable them to freely discuss any other issues they had related to testing. Interviews were of around $30 \mathrm{~min}-$ utes in length for each participant, tape recorded and then transcribed.

Furthermore, field notes were taken during the interview process in order to note expressions and body languages so as to obtain detailed account and better understand the meanings which participants attached to the phenomenon such as expressing fear and pains. Eventually, participants were encouraged to discuss freely by asking questions like do you have any other thing to add to all that you have said? Immediately after the interview, the researcher made notes of the interview process on participants' main responses and showed to them to verify what was written.

Consequently, since the study was carried out in Nigeria, during transit, interview tapes were protected under lock in the personal briefcase of the researcher. In addition, copies of the transcripts were kept in a password protected storage database in the researcher's laptop. Data was analysed by the researcher at the University of Wolverhampton, United Kingdom. The researcher had control and acted on data generated and when not in use, the researcher made sure that data was always kept in a lockable filing cabinet.

\section{Analysis}

The data was analysed thematically and guided by employing the steps proposed by Colaizzi (1978) cited in Polit ${ }^{16}$. Interview tapes were listened to twice initially after the interview process. Then, data was transcribed verbatim from audiotapes, by the researcher closely listening to interview tapes repeatedly for each interview to reveal any unnoticed feature of the interview process. Subsequently, transcribed data were read four times to have a feel of them while making reference to field notes in order to become familiar with the data and gain a sense of the total content of the interview, a process regarded as immersion of data. Interview transcripts were reviewed, significant statements and phrases pertaining to the phenomenon under study were extracted; repetitions and remarks or comments not important to the study were eliminated in order to reduce data into manageable and useful pieces. The root meaning of each significant statement known as formulated meaning as understood by the researcher was spelled out.

Following this related patterns of experiences and ideas embedded in these statements were combined and arranged into a cluster of themes and analysed based on the objective of the research. The researcher engaged in exhaustive description by bringing meaning to themes and patterns thereby making sense of the data obtained. This was achieved by incorporating recurring ideas, patterns of belief and verbatim quotes from data to provide a description of the participants' perspectives. Furthermore, the data was evaluated by determining how useful the data segments were in answering the research question being explored. Therefore, the researcher challenged the patterns in the data and searched for an alternate explanation that was identified and described.

Consequently, the researcher formulated a description of the investigated phenomenon and organised the themes in particular structure to describe participants' opinion. Finally, validation of analysed and interpreted interviews by participants' could not be achieved due to time constraints. However the quality of the study was assessed using Lincoln and Guba's guidelines of trustworthiness: credibility, dependability, transferability, confirmability and reflexivity.

\section{Results}

Five core themes were identified: the symptoms experienced, the influence of friends and relatives, older age associated with increased awareness, accessibility to testing services and the knowledge of the PSA test. In addition, participants' opinions on early testing, and reflections on participation were also identified and noted in the study.

\section{Theme 1: Symptoms experienced}

A finding which was evident throughout all interviews was how symptoms that participants experienced influenced their decision to seek out and take the PSA test. Participants explained how experiencing symptoms such as frequent urination, incontinence and pains had prompted them to visit their doctor, who then referred them to undergo PSA testing. Some of these men reported that they had no knowledge on what the PSA test was and only acted upon the instruction given to them by their doctor because they sought a solution to their problem. Participant A and I exemplified these comments: 
"Em.., actually, eh.., I was having problems, you know, constant urinating from time to time..........I was no longer comfortable with that, so I decided I have to see a doctor so it was when I met with my doctor and explained to him how the whole thing has been disturbing me, so he suggested eh...there could be a possible test I have to run to really eh.., determine the actual cause of the thing" (Participant A).

'I don't know what prostate specific antigen testing is, all I know is that I urinated frequently at regular intervals which is not normal and when I came here I was told the reason why I urinate frequently is that my prostate is enlarged and he referred me to the lab for the test....."(Participant 1)

However, participant $\mathrm{C}$ noted that he was prompted to go for testing by family members who were in the medical profession when symptoms began and as such he had some knowledge about testing prior to consulting his doctor. This point was echoed by others who also had family and friends with medical backgrounds.

"I happen to be from a medical family, some of them are medical doctors, and they said I should go for testing...." (Participant C).

Two of the ten participants indicated that as they became older they were in the habit of regularly visiting the hospital for general checkups whenever they experienced pains in their body. An example is from participant $\mathrm{H}$ who is a patient and also a member of staff at the hospital. He stated that he went to the staff clinic and when the doctor examined him he found that his prostate was enlarged and he was referred for PSA testing.

"Well, am a staff of UBTH and whenever I have something bothering me, I go to the staff clinic, it was in the staff clinic that doctor examined me and found out that my prostate was enlarged and he advised that I do PSA testing" (participant $\mathrm{H}$ ).

Some of these participants visited their doctor after pain persisted for a longer time. For example, Participant D who started having pains in March and didn't seek medical attention for four months.

"Em... I started having pains on my waist in March and the pain persisted, and suddenly, I discovered that I cannot urinate properly, I was having em... inconsistency in my urine..., there was pain around my penile portion, my bladder area, so I decided to come and see the doctor" (participant D).

\section{Theme 2: Influence of friends and relatives}

This study identifies that many men found out about prostate cancer screening from friends who had been diagnosed with prostate cancer themselves. One participant reported that a friend who had spoken about his experience of being diagnosed with prostate cancer and had commenced treatment at an early stage which saved his life, had prompted his own decision to be tested.

"Eh.., I had a friend who went to US, he had some eh.., some feelings and then he went to the hospital, he was diagnosed of prostate cancer antigen, the treatment was, eh..., taken almost immediately and that made him to also survive it and even until today, he's still living" (participant B).

Another participant indicated that knowing friends and relatives who had suffered from prostate cancer was a contributing factor to him accessing testing.

"What happened is that my elder brother was diagnosed of prostate cancer in this hospital........., so I decided that since, em.., am here because my elder brother is also here in the hospital. So, I just decided to do the cancer, the test myself" (Participant G).

Participant B also recalled that watching the health of an in-law deteriorate because his cancer had become terminal, coupled with a friend's experience of prostate cancer made him take issues of his prostate health more seriously.

"......my brother-in-law who had it went to the.. eh, hospital for the test at a terminal stage, he couldn't survive it. So I feel that I should right from that time, I felt that I should start, eh..., going for the checkup, since stitch in time they say saves nine" (Participant B).

This study also discovered that being married, or in a relationship, influenced the drive to undergo testing. Findings show that where men were reluctant to access testing, involvement of their partners in this decision related with uptake. Participant J stated that his wife prompted his decision to come for testing.

"Em..., actually, my wife prompted my decision to come for this testing because em.. She works as a nurse in the Urology department of this hospital and she has been pestering me to come for this test for some time now" (Participant J).

She being a nurse in the Urology department further supports the earlier finding about the direction provided by family members who are health professionals.

\section{Theme 3: Older age and increased awareness}

Some participants indicated that age, and in particular growing old, played an important role in raising their con- 
sciousness and awareness of their health in general. This is exemplified by Participant $G$ and H's comment: "Well, eh, my interest was eh..., was arisen by the fact that, eh.., when people grow old, they're prone to suffer from prostate disease or something of that nature. So, I am prompted to go for the test because I am getting old.....” (Participant G).

"Well, the thing that prompted my decision really to come for this testing, is that.., as one gets older, some of these diseases ..., may show up in one's system..." (Participant H).

The definition of 'old' varied and was not explored amongst the participants; however, all participants were over the age of 40 .

\section{Theme 4: Accessibility of testing services}

Accessibility of testing services also appeared to influence the decision of men to be tested. Some of the patients said that accessing PSA testing was not difficult which made it easier for them to undergo testing. Also, for some participants, such as Participant $\mathrm{H}$ who works as a member of staff at UBTH, working in an environment which provided him with easy and free medical services influenced the regular use of medical services and hence testing. The statement below affirms this:

"I never had any problems accessing testing service because I am a staff of UBTH and whenever I have anything bothering me, I go to the staff clinic...".

(Participant H).

However, many participants pointed out that the lack of easy access to testing services had a negative influence on undergoing testing. This is as presented:

"Yes, eh..., there are problems because eh.., some of these services, one does not even have early information about where to go for some of these services. Not many of these services are even available. So, sometimes it becomes difficulty of one knowing where to go" (Participant F).

They also suggested that this would affect other men's decision to access testing and indicated that more and widespread testing services were required.

\section{Theme 5: knowledge of PSA testing}

Some of the participants said that they gained informa- tion on prostate cancer and testing by reading magazines and newspapers which included information and stories about prostate cancer. Participant $\mathrm{C}$ became aware of the symptoms associated with prostate cancer by reading such information, and since he was experiencing the symptoms outlined he decided to see his doctor.

'T have been reading papers, awake magazine by watch tower society, Jehovah witness wrote about it, it gave me some awareness and there are some newspaper like relations that talks about prostate, when I read those articles, eh.., I said that some of the things they described, I am having the effect, that necessitated my carrying out general test" (Participant C).

Other participants indicated that they were motivated to find out more about specific health issues because they were ageing. Participant E exemplified this in his account and said that he found out through information in local newspapers. This is further echoed by Participant $\mathrm{F}$ who said that the catalyst to him going for the test arose from him hearing about his friends and relatives conditions.

"Em..., I read about it in papers. Eh.., I am very interested in going to the net to find information on different areas of knowledge...... it was in one of such activities that I got to know about eh, prostate eh...prostate specific antigen testing...," (Participant E).

"... one got the information particularly myself, I read papers, read medical papers, medical literature and sometimes one find out from what is happening from friends, the history of some people's health conditions, particularly those of eh..., some friends and relations......" (participant F)

Participants acknowledged that they had increased their understanding of PSA testing by taking part in the study. Some indicated that the study had provided them with the opportunity to air their views, while others commented on how the study might be advantageous in enlightening other men around PSA testing.

"Thank you, very, very much, I am happy, this is a very good opportunity for me to air my own view. Thank you very much. I encourage you to do well in your programme. Thank you very much" (Participant A)

"Thank you very much my daughter, I wish programme you are on, God will guide you, you will get a good number of people who will cooperate with you so that this incidence can be reduced drastically in early stage of life" (Participant D) 


\section{Other findings:}

All participants reported that testing was important to detect abnormalities before they manifested into something more serious or to detect prostate cancer at an early stage for treatment. Most participants believed that it was necessary to take part in routine screening because they were aware that prostate cancer can be present without symptoms. Participant F confirmed

"Early testing is very necessary, in fact if one knew that one was having a situation of that nature, early testing will help to solve the problem at an early stage".

Participant D also felt that routine PSA testing should begin at an earlier age and related this feeling with the issue of HIV/AIDS where testing at an early age is available.

"Eh, I would suggest that eh.., once you get to the age of eh.., say 35 upwards, people should go for just eh.., simple PSA testing, it's simple as they do for HIV, and you do maybe once a month, once in three months or once in six months as the case maybe..." (Participant D).

This study found that these men had gone through a process of self-education following testing and as such they were highly knowledgeable about prostate cancer and the signs and symptoms associated with this disease. Some were also either working in the health care system themselves and/or have health care workers as partners/relations. However, they reported that there was a lack of awareness about PSA testing, prostate cancer itself and its risk factors amongst Nigerian men. Most participants indicated that more awareness should be created on the benefits of PSA screening among men. Participant E indicated this vociferously by stating that

"I would just like to hammer on about early testing and awareness, because if people don't know they won't do the early testing..."

\section{Discussion}

The study identified a number of factors that influence Nigerian men's decision to go for prostate cancer testing. The study shows that the majority of these participants acted on their doctor's instruction after they had come to them complaining of their symptoms. Interestingly, these findings contradict that of other studies which suggest that people mistrusted medical professionals and went to local healers instead ${ }^{17}$.
For many, the involvement of family members was also a contributing factor to them seeking medical advice. This finding is consistent with the study conducted by Jones $e t$ $a l .^{18}$ who noted that knowing that a friend or family member had prostate cancer was important in helping the study participants decide about prostate cancer screening. Also, Evan $e t$ al. ${ }^{19}$ indicated that men with urological symptoms presented for PSA testing after being enlightened by family members who were either in the healthcare profession themselves. This sharing and cascading of information prompted them to become aware and conscious of their own prostate health and seek out information.

This study suggests that men are motivated by fear - i.e. based on the experiences of their friends and relatives the fear that they too would develop prostate cancer motivated them to seek out advice and testing. This point is reflected in a study by Rai et al. ${ }^{20}$ which showed that having friends with prostate cancer was an important stimulus leading men to become anxious about their own risk of prostate cancer. However this finding is contradicted in Held-Warmkessel's study ${ }^{21}$ which identified fear as a barrier to screening as their study found that men are scared of a prostate cancer diagnosis and its treatment.

The study by Davies and Macdowall ${ }^{22}$ suggest that Becker's health belief model (1984) can assist in our understanding of why men may take part in a screening programme. If they perceive themselves at risk, and they believe that the consequences of the illness are serious, then they will seek out health knowledge and screening. This theory could also be applied to the findings in this study; as identified, the group of men were clearly motivated by their beliefs and perceptions of the consequences based on experiences of loved ones.

Being married or in a partnership was also identified as a factor that influenced the uptake of PSA testing among participants. Studies into other health issues affecting men have identified that wives and partners have been instrumental in motivating men to present for testing. This is identified in a study by Evangelista et al. ${ }^{23}$ who note that women were pivotal in assisting men with their understanding around heart disease and encouraged them to find information. Other studies also support this point 
and suggest that the higher rate of prostate cancer among married men may be explained by the role of the spouse in encouraging early detection ${ }^{24}$. Hence, this result may suggest a need to involve relatives, especially spouses, and individuals who have suffered from prostate cancer in health promotional activities targeted at increasing uptake.

Older age resulting in increased awareness around health issues in general was identified as an important predictor of men's prostate cancer screening behaviour. Rai et al. ${ }^{20}$ indicate that as men become older their worries about their health in general increased and as a result they sought out tests such as the PSA test. This health seeking behaviour made them feel that they were acting responsibly and gave them a sense of control over their health.

This study confirms this notion because participants indicated that growing older made them more conscious of their prostate health. Once again, the health belief model can assist in explaining why men became conscious of their prostate health as they increased in age - being aware that age is a risk factor they act upon that knowledge to reduce their risk of developing the disease.

Accessibility of testing services clearly has an influence on testing. Some participants indicated easy access as a stimulator for early testing. While lack of information on where to go for testing delayed some participants from utilizing testing services. Also, limited resources to pay for testing was noted as impeding early testing. This point was supported by a study by Odedina et al. ${ }^{14}$ which argued that access to health care; free screening and transportation were facilitators for prostate cancer screening. The findings therefore underline the need for creation of free or affordable testing centres which are accessible to every group of men in the society.

On the whole, knowledge about prostate cancer, its risk factors and PSA testing were all identified as factors influencing Nigerian men's motivation to be tested. This suggests that knowledge is very important to the issue of PSA testing because, as with other health issues, when men are informed, they can make better health decisions. This is consistent with studies carried out by Sanchez et al. ${ }^{17}$, who found that increased information led to increased testing. Winterich et al. ${ }^{25}$ suggests that this lack of health knowledge amongst African American men results in a reluctance to be screened. It is no surprise that if men don't know about screening then they aren't going to present themselves for a test. Odedina et al. ${ }^{14}$ argue that access to good quality and accurate information through prostate cancer education and awareness initiatives was a key factor that facilitated men to engage in early screening and early detection. Conversely, Evan et al. ${ }^{19}$ argued that high knowledge of PSA testing was associated with lower intentions to undergo testing. This could be attributed to the issue surrounding the controversy on PSA testing in accurately detecting prostate cancer, as educated and knowledgeable men could be well informed about the controversy surrounding testing and therefore decide not to partake in testing. However, in our study none of the participants expressed any views regarding the effectiveness of the test.

Limitations of this study are characteristics of samples obtained, which contained men who were all educated, and at average or above socio-economic status. Hence, the results may not represent the thoughts of men of lower socio-economic groups and may have missed out opinions of men who did not access testing service during the period, when the study was carried out. Notwithstanding, this study has provided useful information on important factors influencing men to undergo testing and therefore highlighted areas to channel health promotional activities towards increasing uptake of testing.

\section{Conclusion}

This study supported much of the existing knowledge on the factors which influence men to undergo testing. This study wires the theory proposed through the health belief model, namely that if men perceived themselves to be at risk then they will take up health preventive measures to reduce their risk of contracting the disease. Participants suggested that men should be more informed of PSA testing through organizing awareness programmes on the benefits on PSA testing in reducing morbidity and mortality from prostate cancer. Thus, an application of the Health Belief Model in channelling health promotional activities will produce positive outcome targeted at increasing screening practices. However, one of the key factors preventing men from undergoing the test was the availability of services and the financial resources to afford this. This is clearly a point that health services need 
to address within the limited economic funds and many health issues affecting Nigerian men.

\section{References}

1. Ajape AA, Babata A, Abiola OO. Knowledge of Prostate Cancer Screening among Native African Urban Population in Nigeria. Nig Qt J. Hosp. Med. 2010; 20(2):94-6. PubMed PMID: 21243859.

2. Woods DV, Montgomery SB, Belliard JC, RamirezJohnson J, Wilson CM. Culture, Black Men and Prostate Cancer: What is Reality? Cancer Control. 2004; 11(6): 388396.

3. Albertsen PC. The unintended burden of increased prostate cancer detection associated with prostate cancer screening and diagnosis. Urology. 2010; 75(2): 399-405. DOI: 110.1016/j.urology.2009.08.078.

4. Mohammed AZ, Edino ST, Ochicha O, Gwarzo AK, Samaila AA. Cancer in Nigeria: a 10-year analysis of the Kano cancer registry. Niger J Med. 2008; 17(3): 280-4.

5. Oladimeji O, Bidemi Y, Olufisayo JA, Sola A. Prostate cancer awareness, knowledge and screening practices among older men in Oyo State, Nigeria. Int Q Community Health Educ. 2010; 30(3): 271-86. DOI: 10.2190/ IQ.30.3.g.

6. Iya D, Chanchani S, Belmonte J, Morris D, Glew RH, VanderJagt OJ. Prostate specific antigen in Africa: a study in Nigerian men. The Nigerian Journal of Surgical Research. 2003; 5(3): 114-19. DOI: http://dx.doi.org/10.4314/ njsr.v5i3.12252.

7. Nwofor ME, Oranusi CK. Cancer of the prostate: Experience at Nnewi, Southeast of Nigeria. Nigerian Journal of Clinical Practice. 2004; 7(2):65-68.

8. Rosser CJ. Prostate cancer-to screen, or not to screen, is that the question? BMC Urology. 2008; 8: 20-22. DOI: 10.1186/1471-2490-8-20.

9. Schröder FH, Hugosson J, Roobol MJ, Tammela LJ, Ciatto, S, Nelen V, et al. Screening and prostate-Cancer Mortality in a Randomized European Study. The New England Journal of Medicine. 2009; 360(13): 1320-1328. DOI: 10.1056/NEJMoa0810084.

10. Andriole GM, Crawford EA, Grubb RL, Buys SS, Chia D, Church TR, et al. Mortality Results from a Randomized Prostate-Cancer Screening Trial. N Engl J Med. 2009; 360(13): 1310-1319. DOI: 10.1056/NEJMoa0810696.

11. Bartsch G, Horninger W, Klocker H, Reissigl A, Oberaigner W, Schönitzer D, et al. Prostate cancer mortality after introduction of prostate-specific antigen mass screening in the Federal State of Tyrol, Austria.
Urology. 2001; 58(3): 417-424. DOI: 10.1016/S00904295(01)01264-X.

12. Horninger W, Berger A, Pelzer A, Klocker H, Oberaigner W, Schönitzer D, et al. Screening for prostate cancer: updated experience from the tyrol study. Current Prostate Reports. 2005; 3(1): 5-10. DOI: 10.1007/ s11918-996-0009-9.

13. Greene KL, Albertsen PC, Babaian RJ, Carter BH, Gann PH, Han M, et al. Prostate Specific Antigen Best Practice Statement: 2009 Update. American Urological Association. 2009; 182(5): 2232-2241. DOI: 10.1016/j. juro.2009.07.093

14. Odedina FT, Scrivens J, Emanuel A, LaRose-Pierre M, Brown J, and Nash RA. Focus Group Study of Factors Influencing African-American Men's Prostate Cancer Screening Behaviour. J Natl Med Assoc. 2004; 96(6): 780-788. PubMed PMID: 15233488

15. University of Benin Teaching Hospital. www.ubth. org/main.php?c=about. Accessed April 20th, 2010.

16. Polit, DF, Beck CT. Essentials of nursing research, generating and assessing evidence for nursing practice. 8th ed. Philadelphia: Lippinocott Williams \& Wilkins; 2008.

17. Sanchez MA, Bowen JD, Hart A, Spigner C. Factor's influencing prostate cancer screening decisions among African American men. Ethn Dis. 2007; 17(2): 374-380. PubMed PMID: 17682373.

18. Jones RQ, Steeves R, Williams I. Family and Friends interactions among African-American men deciding whether or not to have a prostate cancer screening. Urologic Nursing. 2010; 30(3): 189-193. PubMed PMID: 20648856.

19. Evans R, Edwards AG, Elwyn, G, Watson E, Grol R, Brett J, et al. It's a maybe test: men's experiences of prostate specific antigen testing in primary care. British Journal of General Practice. 2007; 57(537): 303-310.

20. Rai T, Clements A, Bukach C, Shine B, Austoker J, Watson E. What influences men's decision to have a prostate specific antigen test? A qualitative study. Family Practice. 2007; 24(4): 365-371. DOI: 10.1093/fampra/ cmm033.

21. Held-Warmkessel J. Contemporary issues in prostate cancer: a nursing perspective. 2nd ed. London: Jones and Bartlett Publishers International; 2006.

22. Davies M, Macdowall W. Using Theory to Guide Changing Individual Behaviour (eds). Health promotion Theory. Open University Press; 2006.

23. Evangelista LS, Kagawa-Singer M, Dracup K. Gen- 
derdifferences in health perceptions and meaning in persons living with heart failure. Heart \& Lung. 2001; 30(3): 167-176. DOI: $10.1067 / \mathrm{mhl} .2001 .114893$.

24. Papatsoris AG, Anagnostopoulos F. Men's behavior towards prostate cancer screening. Postgrad Med J. 2008; 84(988): 57-59.DOI:http://dx.doi.org/10.1016/j. puhe.2008.06.011.
25. Winterich JA, Grzywacz JG, Quandt SA, Clark PE, Miller DP, Acuna J, et al. Men's Knowledge and Beliefs about Prostate Cancer: Education, Race and Screening Status. Ethnicity and Disease. 2009; 19(2): 199-203. PubMed PMID: 19537233. 